\title{
Patterns of Gaming Preferences and Serious Game Effectiveness
}

\author{
Katelyn Procci, James Bohnsack, and Clint Bowers \\ Department of Psychology, University of Central Florida, 4000 Central Florida Boulevard, \\ Orlando FL 32816 \\ \{kprocci,jbohnsack\}@knights.ucf.edu, bowers@mail.ucf.edu
}

\begin{abstract}
According to the Technology Acceptance Model (TAM), important predictors of system use include application-specific self-efficacy, ease of use, and perceived usefulness. Current work with the TAM includes extending the assessment framework to domains such as serious games as well as how other typically under-researched factors, such as gender, affect technology use. The current work reports on how there are gender differences in both game playing behaviors as well as general game genre preferences, offers implications for serious game designers regarding the development of effective learning interventions based on these differences, and finally suggests avenues for future research in this area.
\end{abstract}

Keywords: gender differences, serious games, technology acceptance model, user preferences.

\section{Introduction}

Reports of the success of serious games have echoed across a variety of domains - from improving military operations to generating a more efficient workforce. As an entertainment form, it is generally accepted that more males play video games than females. For example, a study conducted by Bonanno and Kommers [1] found that male junior college students were far more likely than females to play games and that they played for longer, averaging 6.71 hours per week versus only 2.49 hours per week. The researchers found that if an individual reported playing games for 30 hours a week, there was only a $2.1 \%$ chance that they were female. As for game genre preference, females were more likely than males not to provide any game preferences at all, suggesting that they did not play games enough to have a preference. As the science behind serious games continues to develop, it is important to ask what the role of gender differences in gaming habits and preferences plays in how serious games may have differing levels of effectiveness based on prior gaming experience. For example, will male players of serious games learn more because of their own preferences and experiences with the medium? Why would this matter? We will be exploring this issue through the lens of the Technology Acceptance Model (TAM).

\subsection{Technology Acceptance Model and Gender}

The TAM, developed by Davis and colleagues [2, 3], seeks to explain why users choose to interact with technology. Critical to this model are the perceptions of the 
users themselves. The use of a given piece of technology is driven by the intention to use, which in turn develops if the users feel that the technology is both useful and easy to interact with. This is tied to their own self-efficacy, which is the extent to which they believe that they are able to achieve specific goals.

The TAM has been expanded to include earlier predictors of intention to use in information systems. A study by Yi and Hwang [4] confirmed the importance of enjoyment, learning goal orientation, and application-specific self-efficacy when determining the likelihood of students' use of Blackboard, a commonly used internetbased educational content delivery system. Interestingly, they found that applicationspecific self-efficacy was one of the strongest predictors of use, even beyond that of intention to use. Thus, how capable the users felt of being able to use the specific technology was extremely important.

As such, the authors point out the necessity of examining the ways in which individual differences, such as gender, may ultimately affect technology acceptance and use. They cite the work of Gefen and Straub [5], which was the first to highlight how gender is often ignored when applying the TAM to instructional systems. The researchers found that when comparing the attitudes of email usage between the genders, there were differences in social presence, perceived usefulness, and application-specific self-efficacy. However, they failed to find this reflected in actual e-mail use. Regardless, many researchers continue to urge further exploration into the role of individual differences such as gender in all technology acceptance models [6]. Perhaps when given a specific task that is traditionally oriented toward one of the genders, such as with video games, an individual's application-specific self efficacy and perceived usefulness could potentially differ based on whether they are male or female, ultimately resulting in different patterns of use.

\subsection{Applying the TAM to Serious Games}

The TAM has also been applied to serious games. In his unpublished dissertation, Evans [7] was able to successfully apply a modified version of the TAM to the use of a serious game, in which he found that earlier predictors such as learning goal orientation, enjoyment, ease of use, application-specific self-efficacy, and perceived usefulness predicted behavioral intention which then predicted both actual use as well as improved learning outcomes. As the goals of a serious game are to achieve knowledge retention, this is a very important finding. Since research on the TAM suggests that simply feeling capable of playing a specific serious game will be an important predictor of use and also given the extant differences between genders in the gaming domain, it seems pertinent to examine the ways in which gender can affect the predictors of use and overall effectiveness of serious games. Specifically, we feel that examining gender-based differences in preferences for and playing behaviors of entertainment games may provide insight into the ways that serious games may be perceived differently by males and females as well as how that might affect application-specific self-efficacy and, eventually, alter learning outcomes. This will reveal implications for the way serious games are designed. 


\section{Gender Differences in Game Playing Preferences and Behaviors}

Speaking broadly, males seem to prefer action-oriented games and first-person shooters while females are more likely to play and enjoy simpler, more puzzle-like casual games. To explain this, the literature relating to the gender differences in gaming preferences is split between two distinct camps - the neurocognitive and the psychosocial.

\subsection{Neurocognitive Basis for Preferences and Behaviors}

There are some very specific, generally accepted neurocognitive gender differences. Males tend to have an advantage over females in 3D mental rotation, spatial cognition, and visuospatial reasoning. Females have the advantage when tasks involve the need for perceptual speed and fine motor skills and prefer concrete, repetitive activities [1]. Most of the popular commercial video games rely heavily on mental rotation abilities in order to play them. For example, shooters are often male favorites and make use of 3D mental rotation, spatial perception, and targeting, all of which males excel in, while the preferred games of females tend to be casual puzzle games, which require color memory and verbal skills, both of which females are traditionally more adept [8]. Bonanno and Kommers [1] suggest that these natural tendencies translate into game preferences in that individuals will self-select games to play that make use of the skills in which they are naturally better.

\subsection{Psychosocial Basis for Preferences and Behaviors}

Other researchers suggest that the gender differences are based in psychosocial differences. Hartmann and Klimmt [9] found that females, in general, seemed to dislike media and games with negative or sexually-suggestive stereotypes, with violence, and those that placed them into a competitive role. They also found that most commercially available games contained females in sexually suggestive roles, violence, and competition, which may be the reason behind why males are so much more interested in gaming then females as they are not as bothered by these elements. Glazer [10] agrees with the assertion that females are interested in games but the majority of games on the market do not cater to their specific tastes. His research found that games females enjoy feature open-ended exploration, involve team-like play as opposed to actual competition, and promote networking and personal interaction, which are very unlike the first-person shooters and other physical games that seem to dominate the gaming market.

\subsection{Present Study: Gender and Game Preferences}

In summary, the literature suggests that males prefer action-oriented and competitive games while females are more likely to enjoy playing puzzle-based, casual, and cooperative games. While these preferences can be explained from both the neurocognitive and psychosocial perspectives, it is evident that they exist and have consequences in the real-world as reflected in actual gameplaying behavior. 
We have found a similar pattern of preferences and playing behaviors in our own studies of games. We collected survey responses from 760 undergraduate students from a large southeastern university concerning their game playing behaviors and preferences. From these, 245 were males and 515 were female. Respondents reported a mean age of 19.88 years $(S D=3.83)$. When analyzing the data, we uncovered several interesting gender differences. Of those who responded, $71.43 \%$ of males qualified as gamers, which we defined as those who played video games at least twice a week and/or for an average of at least five hours per week, while only $27.57 \%$ of females qualified. Males played an average of 9.01 hours of games per week $(S D=$ $10.95)$ while females played an only an average of 2.84 hours $(S D=3.92)$. These findings are consistent with the previous research. We asked our respondents to rate on a 5-point Likert scale their preferences for a variety of genres as well as list the title of their favorite game, which were coded by genre. We conducted a series of ttests at the .05 level for each genre to determine whether differences in preferences by gender were statistically significant. The differences were clear (see Table 1).

Table 1. Mean genre ratings and reported favorite games by gender

\begin{tabular}{lccrrr}
\hline Genre & Males & Females & $t$ & Fav. (M) & Fav. (F) \\
\hline Strategy & $\mathbf{3 . 4 5}(\mathbf{1 . 1 9})$ & $2.52(1.23)$ & $9.745^{*}$ & $3.72 \%$ & $0.08 \%$ \\
Fantasy/RPG & $\mathbf{3 . 1 8}(\mathbf{1 . 3 7})$ & $2.64(1.35)$ & $5.036^{*}$ & $19.07 \%$ & $9.26 \%$ \\
Action-Adventure & $\mathbf{4 . 0 0}(\mathbf{1 . 0 8})$ & $2.77(1.08)$ & $12.115^{*}$ & $6.51 \%$ & $8.17 \%$ \\
Shooter & $\mathbf{4 . 2 7}(\mathbf{1 . 0 8})$ & $2.79(1.37)$ & $14.550^{*}$ & $45.12 \%$ & $7.63 \%$ \\
Fighter & $\mathbf{3 . 4 5}(\mathbf{1 . 1 9})$ & $2.73(1.37)$ & $6.886^{*}$ & $3.26 \%$ & $2.72 \%$ \\
Simulation & $3.04(1.16)$ & $\mathbf{3 . 5 8}(\mathbf{1 . 3 4})$ & $-5.246^{*}$ & $0.47 \%$ & $12.81 \%$ \\
Classic Arcade & $3.66(1.01)$ & $\mathbf{4 . 3 4}(\mathbf{0 . 9 5})$ & $-8.814^{*}$ & $0.47 \%$ & $9.81 \%$ \\
Card Games & $2.79(1.22)$ & $\mathbf{3 . 4 2}(\mathbf{1 . 2 9})$ & $-6.229^{*}$ & $1.40 \%$ & $0.27 \%$ \\
Quiz Games & $2.66(1.22)$ & $\mathbf{3 . 8 2}(\mathbf{1 . 1 4})$ & $-12.472^{*}$ & $0.00 \%$ & $0.82 \%$ \\
Kids Games & $1.80(0.96)$ & $\mathbf{2 . 4 9}(\mathbf{1 . 1 6})$ & $-7.924^{*}$ & $0.00 \%$ & $0.54 \%$ \\
Sports & $\mathbf{3 . 4 7}(\mathbf{1 . 4 7})$ & $2.58(1.31)$ & $8.176^{*}$ & $17.67 \%$ & $4.63 \%$ \\
Racing & $3.68(1.12)$ & $3.55(1.23)$ & 1.347 & $0.47 \%$ & $4.90 \%$ \\
Puzzle & $3.09(1.43)$ & $\mathbf{4 . 1 4}(\mathbf{1 . 0 5})$ & $-12.491 *$ & $1.40 \%$ & $22.89 \%$ \\
Massively Multiplayer & $\mathbf{3 . 0 3}(\mathbf{1 . 4 3})$ & $2.09(1.20)$ & $9.184^{*}$ & $0.00 \%$ & $6.82 \%$ \\
Online & & & & & \\
Competitive & $\mathbf{4 . 0 8 ( 1 . 2 4 )}$ & $2.36(1.26)$ & $17.383 *$ & $0.00 \%$ & $1.36 \%$ \\
Multiplayer & & & & & \\
\hline
\end{tabular}

Notes: $* p<.001$; standard deviations listed in parentheses. For statistically significant differences, the higher scores, which indicate more enjoyment, are in bold typeface; Fav. refers to percentage of males then females who endorsed that particular genre as their favorite game of those that were able to provide a favorite game (males $n=215$, females $n=$ $367)$. Percentages are rounded to two decimal places, resulting in slightly less than $100 \%$.

The highest rated game genres by males were the action-adventure, shooter, and competitive multiplayer games, while females tended to prefer the classic arcade, quiz, puzzle, and card games. Regarding actual favorite games, by and large, females were far more likely than males to not list any games that they enjoyed playing (28.73\% females as compared to $12.24 \%$ of males), similar to previous findings [1]. Of those that did list a favorite game, the preferred genres as indicated by favorite game for males are by far the more popular and traditional games such as shooters, 
fantasy and role-playing games, and sports games (81.86\% of all favorite genres) as compared to females who endorsed more casual games, such as puzzle games, simulation games, and classic arcade games ( $45.51 \%$ of all favorite genres).

We also asked respondents to indicate whether or not they played and enjoyed playing competitive and cooperative multiplayer games. Males were far more likely to play multiplayer games than females, with $85.31 \%$ of males compared to only $50.39 \%$ of females having reported playing them. Also, $45.71 \%$ of males preferred multiplayer to single-player play while only $19.18 \%$ of females indicated the same. If given the choice between competitive and casual/cooperative multiplayer games, males were divided evenly between preferring either gameplay type $(53.50 \%$ preferred competitive) while females were only slightly more biased toward cooperative multiplayer gaming $(58.48 \%)$. Males were far more likely to play multiplayer games online $(79.84 \%$ of males as compared to $26.26 \%$ of females), but also tended to endorse playing with friends either online or in the same location together $(53.01 \%$ vs. $46.91 \%)$ while females overall preferred to play with friends in the same room $(76.65 \%)$.

\section{Implications and Future Directions for Serious Games Designers and Researchers}

Overall, the data collected from our sample was in support of the current body of literature. Armed with this knowledge, the value of these numbers can be seen as we attempt to extrapolate meaning. Specifically, as more serious games are being developed to be used as educational tools for those in high school and early in students' undergraduate careers, a snapshot of preferences and behaviors may prove to be useful. The inherent mechanism driving the push to use serious games is that they are just that - games. If individuals enjoy a learning intervention, they will engage with it more, and thus hopefully the repeated exposure will result in improved retention. Therefore, understanding and applying player preferences is vital, especially if believing whether one can successfully play a serious game based on personal experience is a factor driving use and eventual effectiveness.

These patterns, regardless of underlying cause, can result in developing stereotype threat. Stemming from the work of Steele and Aronson [11], stereotype threat has been defined as when a negative stereotype about a certain group exists and actually affects the performance of a member of that group if they are aware of the stereotype. Stereotype threat based on gender is no exception $[12,13]$. Here, could females being aware that they are not the typical gamer actually result in decreasing the amount of information that can be learned from a serious game? This also may be detrimental to the application-specific self-efficacy of female serious game players. According to the TAM, it follows that a player's feelings as to whether they can successfully play a specific type of game as well as whether or not it is easily accessible may in fact affect the actual learning outcomes gained as a function of play.

\subsection{Designing Serious Games for Both Genders}

With gender differences that are so clearly present, it becomes important to consider the role a game's genre will play in the overall effectiveness of a given serious game 
especially if the intended audience is composed of both males and females with differing levels of game experience. For example, if a designer creates a competitive multiplayer real-time strategy serious game to educate students about business resource management, the male students may feel more secure and comfortable with playing the game because they might be more familiar with the expected gameplay mechanics and controls. This will result in a greater sense of application-specific selfefficacy, resulting in increased use and improved learning outcomes over those who are not as familiar with this particular style of game. Also, from the perspective of cognitive load, if mental resources are expended on attempting to understand and use a learning tool, only a limited amount of cognitive reserve can be used to actually learn the target content. Those that are more familiar with a specific genre will already know what to expect of the game and excel, while those who are not must first expend the extra mental effort to master the games' mechanics before being able to focus on the educational content. If a given genre is more well-known by only one of the genders, this potentially will result in playing differences and ability that may affect learning outcomes. Thus, something simple yet important such as choosing the appropriate genre for a serious game is a design decision with a very broad impact.

Despite the important differences, it is not feasible to develop two versions of every serious game to cater to gender differences. Given the limited resources available to serious game designers, the focus should instead be on designing a gender-inclusive game. By examining both the literature as well as our data, we can provide some tentative suggestions for future game development efforts that are also avenues for future research.

By mixing elements that cater to both genders' preferences, it may be possible to capture the interest of both. One way to create games that are gender-inclusive could be to create a social environment that is collaboratively competitive. As for cooperative play, our findings suggest that while males have no preference, females prefer to play in the same room with friends. For serious games, this suggests that designers can create games that can be played on the same console or computer together for the potential benefit of both genders. Not only this, from a return on investment perspective, this means fewer pieces of equipment will be necessary to play such games in the educational setting.

Some research suggests that being able to customize the physical appearance of ingame player characters improves females' interest in Massive Multiplayer Online games (MMOs) [14,15]. While we did not find MMOs to be highly rated by females, perhaps including optimal character customization may increase female interest in the serious game without alienating the male players. Also, if you do choose to create a game that is less well-liked or relatively unfamiliar to females, such as a strategy game, you may want to consider taking extra time to develop in-depth gameplay tutorials as well as provide positive and supportive feedback during play. You can also lessen the steepness of the difficulty curve early-on in gameplay to improve the players' sense of application-specific self-efficacy.

Future work should also explore the ways in which these preferences directly affect learning outcomes in serious games. Pertinent research questions could include whether experience with a given genre results in improved in-game performance as well as increased retention, if gamers in general are able to learn more from serious games, as well as the ways in which gender and gaming behaviors interact with genre and 
gameplay mechanisms to affect learning outcomes. This work, along with more research into related questions concerning individual differences, is needed to generate a framework for game development that will improve the overall effectiveness of games for both males and females while maintaining a reasonable return on investment.

\section{References}

1. Bonanno, P., Kommers, P.A.M.: Gender Differences and Styles in the Use of Digital Games. Educ. Psychol. 25, 13-41 (2005)

2. Davis, F.D., Bagozzi, P., Warshaw, P.R.: User Acceptance of Computer Technology: A Comparison of Two Theoretical Models. Manage. Sci. 35, 982-1003 (1989)

3. Davis, F.D.: Perceived Usefulness, Perceived Ease of Use, and User Acceptance of Information Technology. MIS Quart. 13, 319-340 (1989)

4. Yi, Y.M., Hwang, Y.: Predicting the Use of Web-Based Information Systems: SelfEfficacy, Enjoyment, Learning Goal Orientation, and the Technology Acceptance Model. Int. J. Hum.-Comput. Int. 59, 431-449 (2003)

5. Gefen, D., Straub, D.W.: Gender Differences in the Perception and Use of E-mail: An Extension to the Technology Acceptance Model. MIS Quart. 21, 389-400 (1997)

6. Sun, H., Zhang, P.: The Role of Moderating Factors in User Technology Acceptance. Int. J. Hum-Comput. St. 64, 53-78 (2006)

7. Evans, A.W.: Learning for the Next Generation: Predicting the Usage of Synthetic Learning. Doctoral dissertation, University of Central Florida (2009)

8. Sherry, J.L.: Flow and Media Enjoyment. Commun. Theor. 14, 328-347 (2004)

9. Hartmann, T., Klimmt, C.: Gender and Computer Games: Exploring Females' Dislikes. J. Comput-Media Commun. 11, 910-931 (2006)

10. Glazer, S.: Video Games. CQ Res. 16, 937-960 (2006)

11. Steele, C.M., Aronson, J.: Stereotype Threat and the Intellectual Test-Performance of African-Americans. J. Pers. Soc. Psychol. 69, 797-811 (1995)

12. Spencer, S.J., Steele, C.M., Quinn, D.M.: Stereotype Threat and Women's Math Performance. J. Exp. Soc. Psychol. 35, 4-28 (1999)

13. Aronson, J., Lustina, M.J., Good, C., Keough, K.: White Men Can’t Do Math: Necessary and Sufficient Factors in Stereotype Threat. J. Exp. Soc. Psychol. 35, 29-46 (1999)

14. Dede, C., Ketelhut, D., Nelson, B.: Design-Based Research on Gender, Class, Race, and Ethnicity in a Multi-User Virtual Environment. Paper presentation. American Educational Research Association Annual Meeting (2004)

15. Turkay, S., Adinolf, S.: Free to be Me: A Survey Study on Customization with World of Warcraft and City of Heroes/Villains Players. Procedia - Soc. Behav. Sci. 2, 1840-1845 (2010) 